\title{
A ATIVIDADE DOS TRABALHADORES DE ENFERMAGEM NUMA UNIDADE HOSPITALAR: ENTRE NORMAS E RENORMALIZAÇÕES
}

\author{
NURSING WORKER ACTIVITIES AT A HOSPITAL: BETWEEN STANDARDS AND RENORMALIZATIONS
}

\author{
LA ACTIVIDAD DE LOS TRABAJADORES DE ENFERMERÍA EN UNA UNIDAD HOSPITALARIA: ENTRE \\ NORMAS Y RENORMALIZACIONES
}

\author{
Aline Fernanda Fischborn ${ }^{1}$ \\ Moacir Fernando Viegas ${ }^{2}$
}

Resumo Este artigo é fruto de pesquisa que teve como objetivo compreender como ocorrem as relações entre normas e renormalizações numa instituição hospitalar, no contexto da divisão social do trabalho. Os sujeitos foram dois enfermeiros e quatro técnicos de enfermagem do setor de um hospital situado na região do Vale do Rio Pardo, no Rio Grande do Sul. Os métodos utilizados para a coleta de dados foram entrevista semiestruturada, observação participante, análise de documentos e diário de campo. Como resultado, foi possível compreender que o trabalho em saúde gera continuamente, no seu fazer diário, saberes imprescindíveis à sua realização. Porém, pelo caráter espontâneo de sua produção, tais saberes não são reconhecidos. Além disso, apesar de no trabalho prescrito a divisão do trabalho de enfermagem prever normas quanto à divisão de saberes, na atividade concreta de trabalho revelam-se trocas e produção de conhecimentos.

Palavras-chave normas e renormalizações; educação e trabalho; saberes e trabalhadores da enfermagem.
Abstract This article is the result of research aimed at understanding how the relationships between standards and renormalizations occur in a hospital in the context of the social division of labor. The subjects were two nurses and four nursing technicians from a hospital located in the Vale do Rio Pardo region, in the state of Rio Grande do Sul, Brazil. The methods used to collect data were semi-structured interviews, participant observation, document analysis, and field diaries. As a result, it was possible to understand that health works continuously generate knowledge in their daily work that essential for achieving this. However, such knowledge is not recognized because of the spontaneous nature of its production. In addition, although in prescribed work the division of nursing work foresees rules as to the division of knowledge, in the actual work there are both exchanges and production of knowledge.

Keywords standards and renormalizations; education and work; knowledge and nursing workers. 


\section{Introdução}

O tema que nos propomos abordar abrange as relações de trabalho dos profissionais de enfermagem no interior de uma organização hospitalar e suas relações com as práticas, saberes e construção de conhecimentos no trabalho. A questão central que norteou a pesquisa e que deu origem ao presente texto foi a de como ocorrem os processos de educação dos trabalhadores na relação entre normas e renormalizações numa instituição hospitalar no contexto da divisão do trabalho de enfermagem. ${ }^{3}$ Esse questionamento tem origem nas inquietações vividas por um dos autores ao longo dos seus anos de experiência profissional como enfermeira assistencial de um hospital.

No estudo do trabalho em saúde, entendendo-o como atividade humana e espaço de educação, buscamos caminhos para que as relações de trabalho e as práticas educativas inerentes a elas possam ser utilizadas na criação de um novo tipo de conhecimento. Dessa forma, surge também a possibilidade de construir um melhor ambiente para os trabalhadores, permitindo, por parte dos gestores, elaborar propostas de melhorias e transformações no processo de trabalho com base na maior participação deles.

Além do trabalho em saúde, por sua natureza, ser uma tarefa difícil, ele também é complexo e conta com inúmeros participantes envolvidos na execução das ações, pois, além de enfermeiros e técnicos, sujeitos desta pesquisa, envolve médicos, fisioterapeutas, nutricionistas, farmacêuticos, escriturários, funcionários da copa e higienização, bem como os setores de administração, recursos humanos, contabilidade, internação e faturamento, entre outros. A divisão do trabalho em saúde, porém, torna-se evidente quando o assunto é poder de decisão e a ação propriamente dita, pois, além de uma divisão de tarefas, há uma divisão no acesso à tomada de decisões e à participação nessas. Para os técnicos de enfermagem, o controle do processo é limitado, pois executam as ações que outros profissionais da saúde elaboram em conjunto com a equipe administrativa do hospital.

Apesar das diferentes formações profissionais, a relação entre formação e prática não se dá de forma linear, pois nem sempre quem tem menor tempo de estudos teóricos tem menos prática. Especificamente na área da enfermagem, inúmeros técnicos de enfermagem têm maior tempo de experiência prática do que seus superiores, os enfermeiros. Estes, por sua vez, caso não tenham experiência anterior na área da saúde, saem da faculdade com uma bagagem teórica compatível com os anos de estudos, o que não necessariamente implica uma boa prática. Esse profissional, contudo, torna-se responsável por uma equipe de técnicos, na qual muitos dominam a prática. Assim, a hierarquização de funções e saberes gera conflitos e paradoxos nas relações de trabalho. 
Tal realidade afeta a autonomia dos profissionais dentro do processo de trabalho e interfere na construção de conhecimentos gerados nessas relações. No momento em que os técnicos de enfermagem estão trabalhando, eles criam um conhecimento que é só deles e que dificilmente conseguirão transmitir para outros colegas. Esse conhecimento informal baseia-se em experiências subjetivas e escolhas pessoais que imprimem ao trabalho de cada funcionário uma característica própria. Será que os protocolos e técnicas dão conta de tal conhecimento, ou, ao menos, será que os profissionais responsáveis por esses funcionários reconhecem esse conhecimento próprio advindo do trabalho? Sem considerar a subjetividade dos trabalhadores, é possível haver uma boa condução dos processos e fluxos? Encarar o trabalho como atividade humana na qual ocorre um processo educativo nos leva a questionar as contradições implícitas no processo de divisão do trabalho e suas relações com a troca de saberes e autonomias profissionais dos diversos atores envolvidos.

O estudo caracterizou-se como exploratório descritivo com abordagem qualitativa, constituindo-se em análise aprofundada de um setor ambulatorial do qual um dos autores fez parte por dois anos, em um hospital de médio porte da região do Vale do Rio Pardo, no Rio Grande do Sul. Os sujeitos da pesquisa são membros da equipe de enfermagem, especificamente quatro técnicos de enfermagem e dois enfermeiros de um setor do referido hospital. Foram selecionados de forma intencional, levando em conta a maior contribuição que poderiam dar à pesquisa, tendo em vista os anos de experiência profissional, a maior facilidade em expor suas ideias e o tempo disponível para os depoimentos. Todos participaram de forma voluntária e suas identidades foram preservadas, tendo assinado o termo de consentimento livre e esclarecido, aprovado pelo Comitê de Ética e Pesquisa da universidade sob protocolo n. 2.785/2011. Para que as falas não sejam identificadas, os participantes são nomeados aqui por uma letra - ' $\mathrm{T}$ ' no caso dos técnicos de enfermagem, e 'E' no caso dos enfermeiros - seguida por um número arábico.

Os instrumentos de coleta de dados utilizados foram: entrevista semiestruturada; análise de documentos e protocolos institucionais, em especial aqueles que continham as normas e regras de atuação do trabalhador no que tange a questões técnicas do trabalho; observação participante com um roteiro dos pontos a serem analisados; e, por fim, as anotações do diário de campo. Os dados coletados foram compilados e divididos em categorias norteadoras para a análise dos dados.

Como resultado, foi possível compreender que o trabalho em saúde gera continuamente, no seu fazer diário, saberes imprescindíveis à sua realização. Porém, pelo caráter espontâneo de sua produção, tais saberes não são reconhecidos. Além disso, apesar de a divisão do trabalho de enfermagem 
prever normas quanto à divisão de saberes no trabalho prescrito, na atividade de trabalho concreta revelam-se trocas e produção de conhecimentos.

Apresentamos a análise das informações em três eixos: a) Trabalho, experiência e formação do trabalhador em saúde; b) Normalizações e renormalizações no trabalho de enfermagem; e c) Divisão do trabalho e divisão dos saberes.

Antes de expormos a descrição e a análise das informações, faremos uma breve consideração com apoio na ergologia, teoria principal que orientou a presente investigação, sobre o caráter criativo do trabalho em saúde.

\section{O trabalho em saúde como atividade criadora}

Partimos do pressuposto de que o trabalho em saúde, como prática social histórica, não estabelece as divisões técnicas do trabalho apenas como uma simples divisão de tarefas ou funções entre os diversos profissionais, mas envolve também a divisão de saberes e poderes, concretizando a divisão social de classe no trabalho em saúde (Pires, 1998). O trabalho de enfermagem é realizado em grande parte por técnicos de enfermagem e enfermeiros que, de acordo com o seu grau de formação, exercem atividades e ocupam posições distintas na escala hierárquica do trabalho.

Com formação de nível superior, os enfermeiros, além de funções assistenciais e de cuidado relacionadas ao paciente, assumem tarefas administrativas de organização e gestão, o que inclui a supervisão do trabalho dos técnicos. Esses, por sua vez, possuem formação técnica e, por isso, assumem atividades de menor complexidade e de auxílio ao enfermeiro, não participando diretamente nas decisões relacionados ao seu trabalho. Assim, embora o trabalho em saúde apresente características próprias, de maneira geral reproduz as propriedades da divisão do trabalho como um todo, cuja principal característica é a divisão entre trabalho manual e trabalho intelectual4 (Pires, 1998).

Questionamos, porém, até que ponto é possível aceitar a existência de uma rígida separação entre concepção e execução, na medida em que os profissionais que executam os serviços também necessitam refletir e fazer escolhas de acordo com o seu conhecimento informal e sua experiência, ainda mais se considerarmos as características de incerteza que cada vez mais permeiam as atividades de trabalho. Apesar das diferentes formações dos profissionais da enfermagem, a relação entre formação e prática não se estabelece de forma linear, pois nem sempre quem possui menor tempo de estudos tem menores condições de lidar com os desafios da prática. Por sua vez, a hierarquização de tarefas e de saberes gera tensões e contradições nas relações de produção, afetando a autonomia de muitos dos profissionais, já que os trabalhadores são frequentemente impedidos de agir, mesmo sabendo 
como fazê-lo, pois a ação precisa ser validada primeiramente pelo seu superior. Tal autonomia 'vigiada' interfere na construção de conhecimentos gerados nas relações de trabalho.

Não é uma tarefa fácil conceituar categorias fundamentais da teoria ergológica como trabalho e atividade, uma vez que as fronteiras que as separam não são precisas. Muitas vezes, a atividade parece ser quase um sinônimo de trabalho. A compreensão de que a ação humana possui um caráter histórico passa pelo entendimento do conceito de atividade. Para a ergologia, existem singularidades no trabalho efetivamente realizado pelo trabalhador, pois é necessário levar em conta as experiências, valores e conhecimentos adquiridos ao longo da vida de cada sujeito, os quais são componentes inseparáveis da atividade. Para Schwartz (2000), o trabalho é uma experiência de humanização. A permanente modificação das condições materiais de produção está relacionada com a própria natureza humana, que busca sempre e independentemente das condições encontradas uma ação que realize aquilo que é característico de sua humanidade.

Para desenvolver o conceito de atividade, Schwartz vai buscar apoio em Canguilhem, para quem "a vida pode ser definida como a atividade que está em luta permanente com 'a inércia e a indiferença'. Ela é não somente o contrário da inércia, mas uma luta contra a inércia"5 (Schwartz, 2007, p. 122, tradução nossa). Para o autor, a atividade é essa "disposição de produzir a norma na confrontação com o ambiente natural e social"6 e ela "pode ser vista como uma expressão da vida humana enquanto tal, na sua manifestação global, unificada e 'sintética'"'7 (Schwartz, 2007, p. 128, tradução nossa).

A experiência do trabalho é um locus no qual o trabalhador tenta reintegrar, a partir das condições em que se encontra, a unidade do seu ser, a totalidade de sua vida, o que lhe confere, em consequência, um caráter enigmático advindo das numerosas formas de como pode enfrentar as coisas e das escolhas do uso de si que venha a fazer (Schwartz, 2011).

O trabalhador não é passivo diante das normas que antecedem a realização do trabalho, expressas, por exemplo, nos protocolos, tão comuns na enfermagem. A total heterodeterminação da ação, seja qual for o paradigma produtivo, é 'invivível', pois ela resultaria na ausência de vida e de atividade: "O meio é sempre em algum grau infiel, inantecipável" (Schwartz, 2011 , p. 59). Segundo Durrive, o fato de o trabalhador "não aplicar cegamente o prescrito, mas necessariamente pensar", o que leva à ausência de um controle total sobre as "variabilidades do meio pela organização (...), [e] significa dizer que não se pode prescindir da intervenção humana, portanto da reflexão de quem trabalha" (2011, p. 58). É necessário alguém para satisfazer as insuficiências da antecipação, gerir os 'furos' das normas. Como afirma Cunha, esse fato implica que a atividade de trabalho seja uma "situação histórica sempre singular" (Cunha, 2007, p. 5). 
Portanto, reconhecendo a singularidade de cada ação desenvolvida, temos que admitir ser a variabilidade uma questão intrínseca ao processo de trabalho, do que resulta serem as normas padronizadas insuficientes para dar conta do planejado, prescindindo-se da ação do trabalhador. De onde se conclui que existe algo a mais nessa ação que precisa ser entendido e valorizado:

Se o trabalho tem sempre uma dimensão do prescrito, ele tem também uma dimensão histórica, que nos reenvia a uma experiência do uso de si que fazem os trabalhadores. E eles o fazem segundo suas próprias normas, valores e saberes (Cunha, 2009, p. 230).

Pensamos que o conceito ergológico uso de si está intrinsecamente ligado ao fato de que a atividade de trabalho é para o trabalhador um lugar de expressão de sua humanidade, da impossibilidade do trabalho ser simples execução, de não ser atravessado pela história. Há um impulso para a realização daquilo que é humano, um desejo de se expressar como ser social que é impossível separar da ação. Assim, há sempre uma distância (écart) entre aquilo que foi produzido e aquilo que é realizado em ato no trabalho, o que é uma característica universal da produção econômica. Além disso, apesar da possibilidade de certa antecipação da atividade, essa antecipação é parcial, pois a atividade demanda do trabalhador certo grau de iniciativa para que o trabalho seja realizado. E ao ter que agir, é impossível que o trabalhador não entre com o seu ser e faça, então, uso de si.

Como consequência, a atividade de trabalho envolve uma 'tensão problemática', um 'espaço de possíveis sempre a negociar'. Há duas ideias a destacar na frase. Uma refere-se à impossível antecipação total da atividade em decorrência da relação conflituosa entre o uso de si por si e o uso de si por outros (a necessidade de seguir os protocolos). A outra é que, como já afirmado, esse espaço da produção econômica é um lugar de negociação, um lugar de tensões. Para Schwartz (2011, p. 58), a atividade de trabalho é um espaço em que as coisas são negociadas, negociação que se dá entre o "ambiente histórico, social, gerencial, técnico, combinando de maneira muitas vezes perversa, saberes patrimoniais, genéricos e normas de governança assimétricas de grupos sociais diferenciados por seus recursos e poderes", ou seja, as normas antecedentes, e as "obrigações absolutas para se dar aqui e agora normas reprocessadas de trabalho e de vida" (2011, p. 59).

O fato de a atividade de trabalhar implicar processos de renormalização, portanto de humanização, e de que os trabalhadores devam colocar a vida de si próprios no objeto de trabalho significa que é preciso que façam escolhas:

Gerir o aspecto encontro de encontros é gerir aquilo que os outros não geriram antes de nós, e se você faz escolhas, forçosamente tem critérios a partir dos quais 
você faz essas escolhas. Trabalhar sobre essas escolhas é trabalhar sobre você mesmo (Schwartz, 2010, p. 44, grifos do autor).

\section{Trabalho, experiência e formação do trabalhador em saúde}

Um aspecto do caráter formativo que o trabalho apresenta são as transformações que têm lugar nos trabalhadores, comprovadas pelo crescimento pessoal e profissional que eles apresentam ao longo da sua caminhada profissional. De acordo com Schwartz,

nenhuma situação humana, sem dúvida, concentra, 'carrega' com ela tantos sedimentos, condensações, marcas de debates da história das sociedades humanas com elas mesmas quanto as situações de trabalho: os conhecimentos acionados, os sistemas produtivos, as tecnologias utilizadas, as formas de organização, os procedimentos escolhidos, os valores de uso selecionados e, por detrás, as relações sociais que se entrelaçam e opõem os homens entre si, tudo isto cristaliza produtos da história anterior da humanidade e dos povos (2003, p. 23).

Tal fato pode ser percebido nos relatos de duas entrevistadas:

No dia a dia do trabalho, vêm os amadurecimentos relativos a questões de relações interpessoais. (...) Eu tento crescer até porque eu venho de uma história de vida bem atribulada de separações, divisões na família; venho de uma base familiar bem desestruturada, então hoje eu busco isso (....). Essa visão eu fui desenvolvendo ao longo do período de trabalho (...): como que eu vou lidar, tratar bem, perdoar certas coisas, como, por exemplo, se uma pessoa me ofendeu... (T1).

Amadureci muito, cresci, consegui traçar um perfil profissional e, como pessoa, consegui estabelecer para mim o que eu quero enquanto profissional, o que é ser profissional de enfermagem, qual a minha função (E1).

Nesses dois depoimentos, transparece a importância que o trabalho teve no amadurecimento pessoal e profissional de ambas entrevistadas. Ou seja, o trabalho as colocou em situações, às vezes adversas, que as fizeram amadurecer profissional e pessoalmente. Tais situações só são encontradas no trabalho por aqueles profissionais que se deparam com a atividade propriamente dita. Por isso, podemos afirmar que trabalhar é fazer história, é modificar-se constantemente e modificar o mundo.

O amadurecimento da prática e do domínio técnico com as vivências do trabalho também se expressa por meio do que os próprios profissionais denominam como experiência, como aparece no relato a seguir: 
A gente adquire experiência. Quando a gente começa, não tem experiência. No início é muita afobação. Agora não. Eu consigo fazer as coisas com mais calma, eu consigo pensar duas vezes antes de fazer, e antes não. Tu queres mostrar que tu sabes fazer (T4).

Eu acho que se fosse só a graduação eu iria me sentir bem insegura. Eu acho que a faculdade me deu bastante conhecimento teórico, mas a prática mesmo é da minha história no hospital, como técnica, pois na graduação a parte das práticas foi muito rápida (E2).

Ao longo da caminhada profissional, os trabalhadores se dizem mais seguros de sua atuação, por já terem experienciado várias situações na prática. O trabalho desempenha a função de formação, sendo notório que o conhecimento teórico, aquele trazido do aprendizado na formação acadêmica, não é suficiente para que o trabalhador sinta segurança em atuar no campo profissional. É na ação humana, que acontece em inúmeros locais e não apenas nos bancos escolares, que se processa a ação formadora (Arroyo, 1998).

Sabemos que falar sobre experiência é um desafio, pois o que, afinal, podemos considerar como experiência? Ela não é palpável ou algo que possa ser enquadrado em palavras ou conceitos. Não sabemos ao certo como acessá-la, onde ela começa e onde termina. E se, por um lado, a experiência é de difícil conceituação e enquadramento dentro dos tradicionais conceitos acadêmicos, por outro fica claro que ela está presente na rotina diária dos trabalhadores e, portanto, merece ser mais bem analisada. Nesse sentido, a ergologia nos traz a ideia do uso dos saberes informais nas ações de trabalho:

(...) quando frequentamos as situações de atividade e, notadamente, a atividade de trabalho, acredito que podemos dizer que toda situação de trabalho é sempre em parte, e esse em parte é sempre imprevisível (...), aplicação de um protocolo e experiência ou encontro de encontros (Schwartz, 2010, p.42).

Nesse fazer da experiência está a “história de nossos fracassos, nossos sofrimentos, nossos sucessos, nossos engajamentos com uns e outros, atravessados pelas nossas relações com os valores (...). É tudo isso que faz experiência" (Schwartz, 2010, p. 42).

O trabalhador é um sujeito ativo e participante no seu meio de trabalho. Portanto, é impossível aceitar que ele executará uma tarefa tal e qual foi prescrita. Isso nos leva a pensar que o trabalhador produz um tipo de conhecimento no seu ato de trabalho que vai além do saber teórico. Esse conhecimento abarca também o saber prático, a subjetividade de cada um, suas crenças e valores. E esse conjunto de saberes produzido na atividade de trabalho não é neutro, dado que o trabalhador faz escolhas no desen- 
volvimento da atividade (Schwartz, 2003). Mediante essas microdecisões, o trabalhador faz uso de si, ou seja, de seus valores e crenças, e desse saber histórico e singular.

Os serviços em saúde não podem ser totalmente padronizados, pois os profissionais precisam de autonomia para traduzir normas gerais em casos particulares e assim decidir como e qual serviço prestar para atender as necessidades de cada situação. De acordo com Scherer, Pires e Schwartz, “quando a organização diz ao trabalhador que ele deve se ater ao prescrito, ela interdita formas de conhecimento que poderiam problematizar a questão do trabalho como lugar e momento de produção de eficácia" (2009, p.725).

Ao serem questionados sobre as experiências marcantes na sua vida pessoal ou profissional, os trabalhadores mencionaram situações significativas que podem ser facilmente relacionadas com as características pessoais de cada um ao realizar seu trabalho. Sabemos que as experiências anteriores vivenciadas pelos trabalhadores, tanto na vida pessoal quanto profissional, não são esquecidas, assim interferindo no 'como fazer'. Ao ouvir as respostas dadas pelos entrevistados e observar como realizam seu trabalho, a inter-relação entre valores e ação ficou transparente. Dentre inúmeros exemplos encontrados ao longo da pesquisa, trazemos o depoimento de uma técnica de enfermagem que se refere à sua renda.

Preciso dar um jeito de aumentar a minha renda. Quero comprar a minha casa (T5).

Essa trabalhadora se ofereceu para fazer horas extras a fim de aumentar os rendimentos e alcançar seus objetivos pessoais. As escolhas que fazemos podem nos auxiliar no conhecimento da personalidade e dos valores de cada pessoa, os quais o trabalhador não separa da sua atividade diária. Também podemos citar um exemplo ouvido de uma enfermeira ao falar sobre sua vida profissional. Afirma ela:

Quando eu era pequena, eu sonhava em ser ou aeromoça ou executiva, chique e rica, mas estou aqui, enfermeira e pobre [risos]. Queria ter tido mais direcionamento, ajuda da minha família na hora de escolher a minha profissão. Teria sido mais fácil (E1).

Tais comentários feitos ao longo da jornada de trabalho denunciam muito sobre cada trabalhador. Esses são apenas alguns exemplos de como o modo de vida, as conquistas e experiências interferem na atividade de cada um. E essa subjetividade não fica fora do hospital quando o trabalhador vem ao trabalho; está, pelo contrário, sempre presente, influenciando ativamente o desenvolver das atividades do dia a dia.

Outro aspecto que merece ser analisado para podermos entender como um profissional procede no seu trabalho são as escolhas e caminhos que os 
fizeram optar pela área da saúde, em particular ser técnico de enfermagem e enfermeiro. Em tais depoimentos ficou demonstrado que a divisão social precede a divisão do trabalho de enfermagem, na medida em que as escolhas profissionais, em grande parte, são baseadas nas condições financeiras. Seguem dois relatos que expressam essa ideia:

Eu queria ser médica. Aí, por questões financeiras, eu não consegui. Acabei optando pelo técnico, que era o que cabia no meu orçamento (T3).

A escolha pela área da saúde foi muito rápida. Eu acabei o segundo grau, não tinha condições financeiras de fazer uma faculdade, fiquei sabendo que tinha a primeira turma de técnico em Santa Cruz do Sul, que ia ser uma coisa bem boa por causa do emprego, como era a primeira turma de técnico... Até então era só o auxiliar de enfermagem. Não pensei muito ao escolher. Aí a graduação veio porque eu já tava na área, e entre fazer outra faculdade e não ter experiência nenhuma, as chances de eu arrumar um emprego mais rápido era seguir na área. Não que eu não me identificasse com outras áreas. Eu ia gostar de fazer nutrição, veterinária, porque eu sempre gostei de bichos, mas... E era o que tinha na minha cidade (E2).

Nesse último depoimento fica claro que a questão financeira pesou na decisão de fazer um curso técnico, assim como a graduação em enfermagem só pôde ser feita porque a entrevistada já estava trabalhando e assim conseguiu pagar alguns créditos à universidade. Também demonstra a preocupação em fazer um curso que proporcione uma colocação imediata no mercado de trabalho, tanto que, ao optar por um curso de graduação, novamente levou em conta a facilidade de conseguir um emprego na área em que já atuava, em detrimento de ter uma profissão com a qual sempre sonhou.

A idealização da profissão se contrapõe à dura realidade encontrada pela maioria das pessoas, que não podem se dedicar ao 'trabalho ideal' ou sonhado. Elas precisam trabalhar para poder se sustentar. Lembremos que, na nossa sociedade, ter um curso profissionalizante ou técnico já é um caminho para conseguir uma vida digna, embora talvez não a vida idealizada. Podemos afirmar, assim, que a divisão social precede a divisão do trabalho em enfermagem.

\section{Normalizações e renormalizações no trabalho de enfermagem}

Normalizações e renormalizações e o debate de normas daí decorrentes são conceitos mais amplos do que trabalho prescrito e trabalho real e, no nosso entender, ajudam a compreensão do uso de si, ou seja, das formas como os trabalhadores colocam na atividade todo o seu ser. As normalizações são as 
normas e regramentos anteriores à realização do trabalho e compreendem também as normas instituídas pelo coletivo dos próprios trabalhadores. São uma espécie de sedimentação ou institucionalização daquele conhecimento anterior à realização do trabalho, em parte sistematizado nas normalizações administrativas, em parte não sistematizado nas normas instituídas. Já as renormalizações são uma condição sine qua non para que o trabalho aconteça. Como parte da iniciativa do trabalhador, de seu desejo de deixar uma marca, o que é também uma forma de resistir à domesticação, ele precisa se expressar, o que ocorre por meio tanto do corpo quanto da mente, cuja inseparabilidade é reivindicada: “a pessoa remete ao corpo, mas também à história (...), porque a história da pessoa está profundamente engajada no que ocorre"8 na atividade (Schwartz e Mencacci, 2008, p. 10).

É por isso que essas duas dimensões, normalizações e renormalizações do trabalho, ocorrem de maneira inseparável. Uma ligada mais à necessidade de corresponder às normas antecedentes, o que configura uma 'anulação' ou tentativa de anulação do histórico, mais 'morta' do que viva (as condições materiais encontradas), mas da qual não se consegue escapar, e que corresponde ao que Schwartz (2010) chama de uso de si pelos outros. E outra que diz respeito à impossibilidade de anulação do histórico, à inevitável "infiltração do histórico no protocolo prescrito" (Cunha, 2007, p. 5), na medida em que um corpo-mente, quando age, expressa, seja pelo desejo ou pela necessidade da própria concretização da ação, todo um patrimônio cultural, um processo de hominização que o autor chama de uso de si por si. Nele, "é a pessoa que reinventa certa maneira de fazer, de viver, de sobreviver com os outros"9 (Schwartz e Mencacci, 2008, p. 11).

Para Schwartz e Mencacci (2008), ao adentrar num lugar de trabalho vemos que existe uma série de normas, que antecedem à realização do trabalho pelos trabalhadores, do âmbito da organização, do organograma, de procedimentos etc., que são fixadas. Há também normas antecedentes instituídas pelos próprios trabalhadores, normas do grupo, ou seja, 'renormalizações coletivas estabilizadas'. Elas se diferenciam daquelas geradas pela administração, porque não são escritas "e são criadas a partir da atividade de trabalho", dos problemas surgidos nesse âmbito. Há continuidades e descontinuidades entre esses tipos de normas. Já as renormalizações

[são] tudo que eu faço no momento onde, eu, pessoa singular, com meus próprios antecedentes, minhas próprias relações com esse universo de normas antecedentes, eu entro num lugar de trabalho e eu trabalho, é isso que eu chamo de uso de si por si10 (Schwartz e Mencacci, p. 13).

Quando, requisitado pela atividade de trabalho, esse patrimônio histórico entra em ação, recursos muito mais amplos do que os que são demandados 
e explicitados de forma imediata entram em funcionamento, pois é o indivíduo como ser social que é chamado a agir. Para o autor, isso faz com que os processos produtivos, e os conflitos sociais a eles inerentes, sejam incompreensíveis sem a consideração do que ele chama de uma "espécie de ambiguidade entre uso de si por si e uso de si por outros" (Schwartz, 2000, p. 11).

Com apoio no que a ergologia nos traz, concluímos que cada trabalhador age no seu trabalho levando em conta seus valores e experiências. Desse modo, os trabalhadores não fazem a mesma ação da mesma maneira. Para Cunha,

O trabalho, tal como mostrou a ergologia, é lugar de uma distância inevitável entre o prescrito e o real, portanto, lugar de acontecimentos complexos, marcado por decisões instruídas para preencher estas lacunas. A atividade se engendra nessa porosidade do prescrito, em seus interstícios como microdecisões (Cunha, 2007, p. 2).

Como perceber a forma em que, na prática do trabalho, dão-se as relações entre normalizações e renormalizações? Traremos exemplos das práticas que investigamos. O primeiro deles abrange o uso de luva de procedimentos nas punções venosas, que mediante as observações notamos que não se cumprem integralmente, embora essas sejam normas que constam em todos os procedimentos operacionais padrão de punção venosa na instituição. Ignorar o fato de que a luva de procedimento não tem sido utilizada em todas as punções venosas pode trazer sérios riscos para os pacientes e também para os próprios trabalhadores.

Eles alegam vários motivos para o não uso das luvas. Ocorre que alguns equipamentos de segurança, por serem desconfortáveis, podem fragilizar a própria segurança pretendida. Nesse sentido, é preciso renegociar a gestão, pois é obrigação dos responsáveis pela organização reconhecer que as normas não são suficientes para se alcançar um bom trabalho coletivo (Schwartz, 2006). Ou seja, as normalizações não abarcam todas as lacunas da execução de uma atividade. São as chamadas 'brechas das normas', em que um novo saber do trabalhador aparece para dar conta da realização da atividade.

A seguir, temos um exemplo de como o trabalhador utiliza-se de 'jeitinhos' para dar conta das atividades diárias no trabalho, no caso, falando sobre a fixação de cateter.

Às vezes há um paciente idoso que tem a pele extremamente friável [sensível, frágil], que, no tirar ou colocar o micropore, tu vais rasgar a pele, tu não vais fazer a fixação do cateter como está na bibliografia. Tu colocas esparadrapo, envolves uma gaze, uma atadura para proteção. Tem coisas que a gente acaba tendo [que fazer] essas alterações (E1). 
No depoimento, o trabalhador descreve como iria fixar um cateter em um paciente idoso. Nesses casos, ele alega que não pode seguir o que as normas prescrevem como técnica correta, pois isso causaria danos ao paciente. Podemos nos questionar porque não criar uma regra para a fixação de cateter em pacientes idosos. A resposta é simples: certamente o que funcionou e ficou confortável para um paciente não vai funcionar da mesma maneira para outro, mesmo que ambos sejam idosos. Talvez tenhamos um paciente que seja alérgico à atadura, por exemplo. Assim, não podemos seguir um padrão para todos os pacientes idosos.

Outro exemplo percebido foi no uso do eletrocardiograma (ECG). Durante um período ao longo da pesquisa, o setor analisado teve um problema com um dos seus aparelhos de ECG. Ouviu-se de uma enfermeira que trabalha há alguns anos no hospital uma sugestão que poderia ser dada apenas por alguém que trabalha há certo tempo na área:

Liga o fio terra deste ECG que está estragado na torneira, aí não dá interferência. Nós fazíamos muito isso na Ala x [unidade de internação clínica], de noite, quando eu era técnica (E2).

Essas singularidades e variações de cada situação de trabalho demonstram a riqueza do saber que o trabalhador cria na sua atividade. Não é um saber que se enquadre em conceitos teóricos, pois ele é instável e dinâmico. Ele resulta em algo novo, porque as situações são sempre novas. Para Schwartz:

Estes saberes produzidos na atividade de trabalho não podem ser cercados, circunscritos, antecipados, dados através da descrição de uma situação de trabalho particular, como se os trabalhadores estivessem, por necessidade, mecanicamente, conduzidos a produzi-los, considerando as obrigações desta situação. Isto seria retornar a uma determinação exclusiva pelas normas antecedentes e, portanto, não mais compreender como os homens fazem sua história, fazendo história no seu trabalho (Schwartz, 2003, p. 26).

Seguem mais alguns exemplos de como os trabalhadores acessam constantemente seus saberes e fazem, assim, as renormalizações necessárias no seu trabalho diário:

Eu preciso elevar os membros do paciente e eu não tenho coxins adequados. O que fazer? Se eu não tenho coxins, eu não vou elevar? Não, eu vou usar uma escada, um travesseiro, um cobertor. Então eu acho que a criatividade na atividade desenvolvida é fundamental (E1).

A gente aprende mesmo [é] fazendo, pois o paciente, quando chega aqui, por exemplo, um esfaqueado, ele chega todo sujo, é briga ou... Então, lá no livro, eles 
estão bonitinhos, mas quando a gente pega eles aqui é diferente. A gente aprende lá, mas na prática é diferente. Tu tens que te deparar com essa situação para dizer que aprendeu, porque às vezes depende muito do local onde ele foi esfaqueado, às vezes vem com as vísceras todas expostas, às vezes só no braço, no rosto, então é diferente ali, manusear (T4).

Nesse saber da prática ou da experiência que o trabalhador nos relata está a subjetividade de cada trabalhador. Esse é um saber que não é geral, e sim singular, portanto não conceitual. Segundo Schwartz (2003, p. 27), esse saber não tem estatuto de objetividade, de evidência dedutiva, próprio aos conhecimentos das ciências da natureza. O sentido das renormalizações que o trabalhador faz ao realizar sua atividade, de acordo com o autor, não está inscrito em parte alguma, pois ele remete às pessoas.

\section{Divisão do trabalho e divisão dos saberes}

As observações e entrevistas nos permitiram reafirmar o questionamento sobre em que medida a hierarquização presente no organograma das empresas, ou, neste caso, do hospital, corresponde à hierarquização do conhecimento utilizado pelos trabalhadores que exercem diferentes cargos. E, mais especificamente, em que medida a divisão do trabalho de enfermagem determina a divisão dos saberes presentes na atividade.

$\mathrm{Na}$ fala dos técnicos de enfermagem transparece a ideia de que o saber do enfermeiro tem maior valor ou é sempre o mais correto. Nas referências ao enfermeiro, aparecem expressões como "a pessoa que tem mais conhecimento", "tem faculdade", "ele sempre tem mais coisas para passar". Assim, parece que o saber acadêmico prevalece como o saber da prática.

Não queremos provocar uma discussão em torno da formação universitária ou indicar que ela é insuficiente, mas sabemos que em grande parte esses depoimentos estão embasados na relação hierárquica que o enfermeiro tem com a equipe, e não no acúmulo de mais saberes deles. Não necessariamente a posição do enfermeiro na divisão do trabalho de enfermagem corresponde ao acúmulo de saberes. Porém, algumas vezes se desenha uma situação na qual esses saberes precisam ser 'esquecidos' pelos técnicos diante da relação hierárquica nas relações de trabalho vivenciadas. Podemos pensar na situação em que o enfermeiro precisa se ausentar do setor por algum motivo. Em tal situação, o técnico de enfermagem tenta dar conta do trabalho sem o enfermeiro. E nas nossas observações percebemos que o técnico o faz de forma magistral.

Portanto, podemos nos questionar: se, no momento da ausência do enfermeiro, o técnico é capaz de realizar as funções, porque em outro mo- 
mento, quando o enfermeiro está presente, isso não ocorre? Para onde vai o conhecimento do técnico naquele momento? Com certeza se mantém com o trabalhador, porém ele é impedido de usá-lo devido à divisão do trabalho de enfermagem e à sua consequente hierarquização. A situação se assemelha a um jogo de esconde e mostra de saberes do trabalhador, em especial do técnico, que precisa saber as normas desse jogo apuradamente.

Ao longo das observações, a dificuldade em definir, em entender os papéis e limites de atuação de cada profissional da enfermagem foi presenciada inúmeras vezes. Podemos pensar que essa dificuldade ocorre justamente porque em algumas situações esses papéis são claros e definidos e, em outras, essa definição é maleável, solúvel ou invisível. Resgatando o que a ergologia nos afirma sobre o assunto, percebemos que é impossível a total antecipação ao trabalho, pois o trabalhador sempre fará uso de si.

A divisão do trabalho, portanto, não impede que, na realização da atividade ou no trabalho real, ocorra a fusão de papéis entre os membros da equipe de enfermagem, a troca de informações e, com isso, a possibilidade de formação no trabalho. Assim, quando falamos do trabalho real, nem mesmo a divisão do trabalho na enfermagem pode impedir o processo de crescimento pessoal e profissional dos trabalhadores. Porém, quando falamos do trabalho prescrito, das normas e técnicas de atuação, a divisão do trabalho acarreta a divisão dos saberes, visível na relação hierárquica entre enfermeiros e técnicos de enfermagem.

\section{Considerações finais}

Ao longo da pesquisa, foi possível compreender que o trabalho está permeado por ações de normalizações e renormalizações. Também percebemos que o contato com o trabalho é fundamental na formação do trabalhador, demonstrando os limites da formação acadêmica ou do saber teórico desvinculado da prática. O trabalho oportuniza a experiência de situações que não poderiam ser vividas de outra forma pelo trabalhador. Assim, a troca de conhecimento entre a equipe, o convívio com os pacientes e o amadurecimento pessoal e profissional advindo dessas relações são práticas sociais de formação do trabalhador. Estamos afirmando, desse modo, que o trabalho é um campo riquíssimo para auxiliar na formação desses trabalhadores.

Quando fazemos a discussão sobre normalizações e renormalizações, ingressamos num campo cujo terreno é movediço. Um campo delicado no qual, muitas vezes, a diferença entre ambas é de fácil percepção, porém de difícil reconhecimento e valorização. Ficou demonstrado que os valores intrínsecos do trabalhador interferem no 'como fazer' dele. O que não nos parece tão claro é a valorização do conhecimento gerado 'do fazer diferente' 
ou do saber que se materializa quando o trabalhador desempenha sua atividade. Esse saber parece não ser tão importante para os gestores, e nem também para os próprios trabalhadores - talvez porque não seja palpável, não se consolide em documentos escritos, protocolos ou conceitos. Esse saber é informal, histórico e construído no dia a dia. É um saber produzido somente no trabalho.

A divisão do trabalho na enfermagem perpassa toda essa pesquisa como uma 'força' muito rígida e fixa, que exerce e demonstra poder de ação de uns sobre outros. Em contrapartida, o saber produzido no trabalho é de difícil visualização e não linear. Temos uma hierarquia nas relações de trabalho de enfermagem, mas o saber produzido pelos trabalhadores não acompanha essa linha hierárquica e não pode ser aprisionado por ela, ou seja, não pode ser controlado. Essa é uma contradição gerada pelas relações de trabalho e pelo processo de formação dos trabalhadores.

A investigação contribuiu para reforçar a ideia de que o processo de formação dos trabalhadores no trabalho é algo dinâmico, inerente à realização da atividade e de grande importância para o trabalhador e para o próprio processo de produção. As normas e as renormalizações perpassam todas as ações dos trabalhadores, sendo a atividade realizada um diálogo permanente entre saber formal e informal.

A tomada de consciência dos trabalhadores em relação à importância desse saber singular, inédito, inevitável, proveniente da sua prática, pode ser um caminho para eles interferirem e transformarem seu ambiente de trabalho, tornando-o mais humanizado e acolhedor.

Algumas perguntas que não foram respondidas pela pesquisa, mas que continuam nos instigando, são: como mudar rotinas, fluxos e procedimentos levando em conta o saber intrínseco do trabalhador? Como valorizar esse saber numa relação profissional regida pela divisão do trabalho? Como gerir uma equipe se afirmamos que cada indivíduo age de forma diferente diante da mesma situação de trabalho? E, por fim, qual o papel das escolas técnicas e da universidade na formação dos futuros trabalhadores, tendo em vista que o contato com a prática do trabalho se mostra fundamental para a construção do conhecimento do trabalhador? 
Resumen Este artículo es fruto de investigaciones que tuvieron como objetivo comprender cómo suceden las relaciones entre normas y renormalizaciones en una institución hospitalaria, en el contexto de la división social del trabajo. Los individuos fueron dos enfermeros y cuatro técnicos de enfermería del sector de un hospital situado en la región de Vale do Rio Pardo, en Río Grande do Sul, Brasil. Los métodos utilizados para la recolección de datos fueron la entrevista semiestructurada, observación participante, análisis de documentos y diario de campo. Como resultado, fue posible comprender que el trabajo en salud genera continuamente, en su cotidiano quehacer, saberes imprescindibles para su realización. No obstante, por el carácter espontáneo de su producción, tales saberes no son reconocidos. Además de ello, a pesar de que en el trabajo determinado para la división del trabajo de enfermería se prevean normas con relación a la división de saberes, en la actividad concreta de trabajo se revelan intercambios y producción de conocimientos.

Palabras clave normas y renormalizaciones; educación y trabajo; saberes y trabajadores de enfermería.

\section{Notas}

1 Universidade de Santa Cruz do Sul, Departamento de Enfermagem e Odontologia, Santa Cruz do Sul, Rio Grande do Sul, Brasil.

$<$ fischborn@unisc.br>

Correspondência: Av. Senador Pasqualine, n. 344, apto. 402, CEP 96820-050, Santa Cruz do Sul, Rio Grande do Sul, Brasil.

2 Universidade de Santa Cruz do Sul, Programa de Pós-Graduação, Departamento de Educação, Santa Cruz do Sul, Rio Grande do Sul, Brasil.

$<$ mviegas@unisc.br>

3 Estamos nos referindo à dissertação de mestrado Formação dos trabalhadores no contexto da divisão do trabalho de enfermagem: entre o prescrito e o real, apresentada em março de 2012, na Universidade de Santa Cruz do Sul, por Aline Fernanda Fischborn.

4 Talvez fosse mais correto, considerando as mudanças atuais no paradigma produtivo e a criação de uma economia informacional (Castells, 1999), e ainda mais porque o trabalho em saúde se caracteriza por ser um serviço, falarmos de divisão entre trabalho simples e trabalho complexo. De todo modo, mantemos aqui as categorias tradicionais, pois entendemos que o trabalho do técnico de enfermagem, em que pesem as grandes diferenças do trabalho realizado em uma fábrica, tem muito de manual se contraposto ao trabalho do enfermeiro.

5 “La Vie peutêtre définie à travers l'activitéqui est en lutte permanente avec l'inertie et l'indifférence".

6 "Disposition à produire de la norme dans la confrontation à l'environnement naturel et social".

7 "Peutêtre vue comme une expression de la vie humaine entant que telle, dans sa manifestation globale, unifiée et 'synthétique'". 
8 "La personne renvoi eaucorps, mais aussi à l'histoire (...) parce que l'histoire de la personne est profondément engagée dans ce passage là".

9 "C'est la personne qui réinvente une certa inemanière d'être, de vivre, de survivre, de survivre avec les autres".

10 " $\mathrm{C}$ 'est tout ce que je fais au moment où, moi, personne singulière, avec mes propres antécédences, mes propres rapports à cet univers des normes antécédentes, j'entre dans le lieu de travail et je travaille, c'est ce que j'appelle l'usage de soi par soi".

\section{Referências}

ARROYO, Miguel G. Trabalho: educação e teoria pedagógica. In: FRIGOTTO, Gaudêncio (org.). Educação e crise do trabalho: perspectivas de final de século. 2. ed. Petrópolis: Vozes, 1998. p. 138-165.

CASTELLS, Manuel. A era da informação: economia, sociedade e cultura. v. 1. São Paulo: Paz e Terra, 1999.

CUNHA, Daisy M. Notas conceituais sobre atividade e corpo-si na abordagem ergológica do trabalho. In: REUNIÃO ANUAL DA ANPED, 30, 2007, Caxambu. Anais... Caxambu: Associação Nacional de Pós-graduação e Pesquisa em Educação, 2007. p. 1-15.

CUNHA, Daisy M. Lições de pedra: das minas de saberes e valores. Educação Unisinos, São Leopoldo, v. 13, n. 3, p. 228-235, set.-dez. 2009.

DURRIVE, Louis. A atividade humana, simultaneamente intelectual e vital. Trabalho, Educação e Saúde, Rio de Janeiro, v. 9, n. 1, p. 47-67, 2011.

PIRES, Denise. Reestruturação produtiva e trabalho em saúde no Brasil. São Paulo: Annablume, 1998.

SCHERER, Magda D. A.; PIRES, Denise; SCHWARTZ, Yves. Trabalho coletivo: um desafio para a gestão em saúde. Revista de Saúde Pública, São Paulo, v. 43, n. 4, p. 721725, 2009.
SCHWARTZ, Yves. Trabalho e uso de si. Pro-Posições, Campinas, v. 5, n. 1, p. 34-50, 2000.

SCHWARTZ, Yves. Trabalho e saber. Trabalho e Educação, Belo Horizonte, v. 12, n. 1, p. 21-34, 2003.

SCHWARTZ, Yves. Entrevista. Trabalho, Educação e Saúde, Rio de Janeiro, v. 4, n. 4, p. 457-466, 2006.

SCHWARTZ, Yves. Un bref aperçu de l'histoire culturelle du concept d'activité. @ctivités, v. 2, n. 4, p. 122-133, 2007.

SCHWARTZ, Yves. A experiência é formadora? Educação \& Realidade, Porto Alegre, v. 35, n. 1, p. 35-48, jan.-abr. 2010.

SCHWARTZ, Yves. Qual sujeito para qual experiência. Tempus: Actas de Saúde Coletiva, Brasília, v. 5, n. 1, p. 55-67, 2011.

SCHWARTZ, Yves; MENCACCI, Nicole. Trajectoire ergologique et genèse du concept d'usage de soi. Informática na Educação: Teoria \& Prática, Porto Alegre, v. 11, n. 1, p. 9-13, 2008.

Recebido em 19/12/2012

Aprovado em 01/09/2014 